\title{
The Effect of Using I-CHAT Medium on Deaf Students Ability to Arrange Sentence Structures
}

\author{
Utomo, Ganis Sukohanayu \\ Special Education Study Program \\ Universitas Lambung Mangkurat \\ Banjarmasin, Indonesia \\ bekantan_mtp@yahoo.co.id, ganissukohanayu@ymail.com
}

\begin{abstract}
On the initial problem of this study, it was found that the deaf students made mistakes in composing a correct sentence structure. Meanwhile, lecturers require these students to master the correct sentence structure. Therefore, this study aims to determine the effect of I-CHAT as a learning medium on the students' ability to write correct sentence structures. This study used a quasi-experimental design research with one group pretest-posttest research design. The subjects of this study were five deaf students of University of Lambung Mangkurat. The data was collected using a test to compile sentence structures related to the course of Child Education with Intellectual Obstacles, observation, and documentation. The data were analyzed using Wilcoxon Ranking Test (Wilcoxon Signed Rank Test). The results of this study showed that the deaf students' ability to structure sentences improves from mean score 34 to 54 after learning using I-CHAT media. Statistical calculation using Wilcoxon Signed Rank Test proved that there were differences between mean scores of pre-test and post-test of the sample after implementing I-CHAT media. It can be concluded that the use of I-CHAT media improves the ability of the deaf students to structure sentences.
\end{abstract}

Keywords-composing sentence structure, I-CHAT media, deaf students.

\section{INTRODUCTION}

A language is a tool for communicating used by individuals in communicating with each other. This means that if a group of individuals has the same language, they can exchange ideas about everything that is experienced both concretely and abstractly. To learn languages, individuals must be able to distinguish between the sounds of letters, words, or sentences. In addition, individuals can socialize with their environment with language, interact with one another as well as language [1].

Every language has certain rules or rules, both regarding sound, form, and sentence. The rules of language are important to be mastered so that there is the agreement between fellow language users, thus avoiding errors in their use. The rules in language are called grammar and one of the sub-topics in Indonesian grammar is the syntactic or sentence field. Syntax is part of grammar that studies the basics and the process of forming sentences in a language. Syntax has several aspects of the discussion, one of which is sentence structure [2], [3].
Sentences arranged by deaf children in writing are difficult to understand because they are often not structured or even the structure of the sentence is often reversed. For example, the correct sentence structure is "I have eaten" but deaf children compile it into "I eat already" which makes the structure of their sentence wrong. Placement and selection of inappropriate words by deaf children makes the sentence less easy to understand [4], [5]. Here are examples of sentences made by deaf children on their Facebook status "Today is a holiday with them", from that sentence we may understand what is meant, but the sentence structure is not correct. This is in line with the theory that children with hearing impairment are children who experience hearing loss or lack of ability due to damage or nonfunctioning of some or all hearing devices, so that they experience obstacles in the development of speech and the acquisition of language, and cannot understand what is seen or acquired through various external stimuli, especially through the sense of hearing. This has an impact on incomplete receptive language acquisition of deaf children because not everything they see can be understood [3], [6].

Communication barriers that occur in children with hearing impairment are caused by the inability of hearing which ultimately requires deaf children to use vision in their receptive language acquisition. This has an impact on the incomplete acquisition of receptive language of deaf children because not everything they see can be understood. Therefore, if a deaf child makes a sentence, the sentence structure is not uncommon wrong [7].

Based on a preliminary study of deaf students, there are some obstacles that generally occur in terms of writing including irregular (structured) sentences that are difficult to understand. For example, I eat already. The placement of words in the sentence is less precise, making the sentence less easy to understand. The words in sentences do not have a relationship so that the sentence line is not clear. Besides that, the way the lecturer communicates with deaf students also does not use correct (unstructured) sentences, so that deaf students become accustomed to speaking or writing using unstructured sentences. Frequent use of unstructured sentences as above, resulting in messages delivered by deaf students when communicating cannot be understood by people hearing. This is very influential in the career and future of deaf students themselves. Therefore, there needs to be an effort to develop 
the potential of deaf students, namely the ability to make structured sentences. Deaf students need to get language learning as effective as possible. One of them is supported by the media that can help improve the ability of deaf students to make structured sentences. Increasing the ability to make structured sentences will further facilitate the communication process between deaf students and those who hear in general [8].

One of the learning media intended to help deaf students in improving the ability of sentence structure is I-CHAT (I Can Hear and Talk). This medium is a portal consisting of applications that function as a tool for the deaf in acquiring language [9]. Therefore, lecturers or teachers need to know and implement effective media in supporting learning. The research on the use of I-CHAT medium needs to be done. The study was conducted to obtain an overview of the effectiveness of the media in improving the ability to structure the sentence structure for deaf students at Lambung Mangkurat University. The purpose of this study was to determine whether I-CHAT medium as a learning medium for Intellectual Barriers Children Education courses could improve the ability to compose sentence structures and add the variety of learning media to deaf students at Lambung Mangkurat University.

\section{METHOD}

The approach used in this study was a quantitative approach, in which the data generated in the form of numbers and analysis using statistics. In general, quantitative approaches can also be implemented as descriptive research. The design of this study was a quasi-experimental study with one group pretest-posttest design [10]. This study did not use a comparison class. It used an initial test so that the magnitude of the influence of using the I-CHAT medium in the ability to arrange the sentence structure. In this study, the deaf students were first given an initial test (pretest) to determine the extent of initial ability, after being given an initial test, the deaf students were given treatment (treatment), then deaf students were given a final test (posttest). The total subjects taken in this study were five deaf students. They are students who are studying at Lambung Mangkurat University in Banjarmasin, specifically the Special Education program. Data collection techniques used in this study were monitoring, observation techniques, and tests results. The research instruments used were test instruments, observation instruments, and documentation instruments. In analyzing the data in this study, the researcher used non-parametric statistical data analysis techniques, namely Wilcoxon Ranking Test (Wilcoxon Signed Rank Test) which was marked with a symbol T. This technique was used because it was adapted to the type of experiment and type of data. The researchers used One Group Pretest-Posttest Design that is before the treatment was given a test and after the treatment was given a re-test. The treatment was carried out within a certain period.

\section{RESUlt AND DISCUSSION}

The results of the descriptive analysis of data before and after learning can be described in Table 1:
TABLE I. RESUlT OF THE DESCRIPTIVE ANALYSIS VARIATIONS

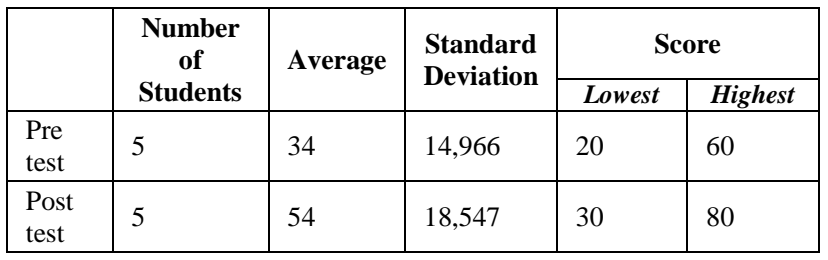

This result is also supported by the results of tests with nonparametric statistical analysis techniques which can be presented as follows:

TABLE II. TABLE OF CALCULATION OF WILCOXON MARKED RANKING TEST ANALYSIS (RANKS)

\begin{tabular}{|c|c|c|c|c|}
\hline & & $\mathbf{N}$ & $\begin{array}{l}\text { Mean } \\
\text { Rank }\end{array}$ & $\begin{array}{c}\text { Sum of } \\
\text { Ranks }\end{array}$ \\
\hline Post - Pre & $\begin{array}{l}\text { Negative Ranks } \\
\text { Positive Ranks } \\
\text { Ties } \\
\text { Total }\end{array}$ & $\begin{array}{l}0 \mathrm{a} \\
5 \mathrm{~b} \\
0 \mathrm{c} \\
5\end{array}$ & $\begin{array}{l}, 00 \\
3,00\end{array}$ & $\begin{array}{l}, 00 \\
15,00\end{array}$ \\
\hline & & & & $\begin{array}{l}\text { st }<\text { Pre } \\
\text { st }>\text { Pre } \\
\text { st }=\text { Pre }\end{array}$ \\
\hline
\end{tabular}

TABlE III. TABle of Statistics Test Result (Test Statisticsa)

\begin{tabular}{|l|l|}
\hline & Post - Pre \\
\hline Z & $-2,041 \mathrm{~b}$ \\
Asymp. Sig. (2-tailed) & 041 \\
\hline \multicolumn{2}{|c|}{ a. Wilcoxon Signed Ranks Test } \\
\multicolumn{1}{|c|}{ b. Based on negative ranks }
\end{tabular}

The data were analyzed using the SPSS data processing program. From these results, it can be seen that the result of negative rank mean is 0 with the sum of the rank of 0 and positive rank of 3.00 with a sum of the rank of 15.00. In this statistical test produced $\mathrm{Z}$ count -2.041 with a probability of 0.041 which is below 0.05 . Therefore, the probability value of $\mathrm{Z}$ calculated from the Wilcoxon Signed Rank Test is smaller than the error probability of $5 \%(\alpha=0.05)$, and from the results of descriptive analysis obtained, the average of the pre-test was 34 and the posttest was 54. Therefore, the hypothesis in the study is "The use of I-CHAT medium can improve the ability to structure the sentence structure for deaf students at the University of Lambung Mangkurat".

In this study, the subjects of the study for treatment was deaf students at the University of Lambung Mangkurat. This is in line with what was stated by [11] that children who have difficulty hearing also have problems in processing language information, especially in structuring sentences through hearing so that they need to use hearing aids and good learning media to support learning [6].

During this time, at the University of Lambung Mangkurat especially in the Special Education program conducted learning using the lecture method and concrete media around. The use of concrete media is indeed good for deaf students in getting to know their surroundings, but not yet effective enough to improve language skills, especially the ability to structure their sentences. Therefore, a more effective learning media is needed to improve language skills, especially the 
ability to structure the sentences of deaf students [12], [13]. The learning medium used in this study is the I-CHAT medium designed by PT. Telkom for deaf children and the surrounding community to be able to help improve their language skills [7].

The problem studied in this study is the ability of deaf students in Lambung Mangkurat University to arrange the sentence structure properly and correctly so that it makes it difficult for them to learn the language and also experience errors in the delivery of information or communication with others, and makes it difficult for lecturers to do classroom learning.

Learning that applies I-CHAT medium makes the subject look interested in the media, while the subjects learning process is calmer and focused on paying attention to the material contained in the I-CHAT medium. Because the subject is focused on listening to the media, this affects the learning achievement of Child Education with Intellectual Obstacle courses, so that when working on the test the subject is more serious in working on it [14]. This is in line with what was stated by Salim Hadi (2005: 26) that learning media that are interesting and easy to use can improve and direct children's attention can lead to learning motivation in children, direct interaction between children and their environment, and allow children to learn accordingly with his abilities and interests which will later affect children's learning achievements [15], [16].

\section{CONCLUSION}

Based on the results of the discussion and descriptive quantitative analysis and testing using the Statistical Package For Social Science (SPSS) application in this study, it can be concluded that the use of I-CHAT medium can improve the ability to structure the sentence for deaf students at Lambung Mangkurat University. Based on the results of the research and discussion that has been explained previously, some suggestions provided from the results of this study are as follows: this study is expected to be useful for certain parties relevant to this study, the universities are expected to consider the result in making policies regarding active and interesting learning activities, especially for deaf students, for example by using I-CHAT learning medium as one of the learning media references to improve activity, enthusiasm, and ability to structure sentences. In short, this aims to be an inspiration to improve the quality of learning by carrying out more active, effective and enjoyable learning for students.

\section{REFERENCES}

[1] B. Melinda, "Comparison of Pre-test and Post-test scores ability to Arrange Sentences of Deaf Children through the Use of I-CHAT Media," Journal of Special Education, vol. 1, no. 2, 2016.

[2] H. Alwi, Kamus Besar Bahasa Indonesia. Jakarta: Balai Pustaka, 2003.

[3] L. Lindawati, "Imperative Sentence Language of the Tukang Besi Islands," Journal of Humanika, vol. 3, no. 14, 2015.

[4] H. Handayani, E. Sri, P. Priyono, and A Mohammad, "Increased Understanding Of Fairy Tales Of Deaf Children Through Simulation Based Learning," Indonesian Journal of Disability Studies (IJDS), vol. 4, no. 1, pp 9 - 15, May 2017.

[5] Y. A. Widia, "Obtaining Vocabulary for Deaf Children Based on the Indonesian Language Class at SDLB Karya Mulia II Surabaya: Psycholinguistic Studies," Skriptorium, vol. 1, no. 2, pp. 129 -142, Apr. 2007.

[6] E. Melinda and I. Heriyati, Communication Building, Perception of Sound \& Rhythm. Jakarta: PT. Luxima Metro Media, 2013.

[7] L. Hidayat, "The Influence of Learning with Multimedia I-CHAT Against the Treasury Mastery of the Grade 1 Deaf Children at the Sragen State SLB 2013/2014 Academic Year", Education Journal, vol. 1, no. 2, 2014.

[8] N. Mahnun, "Study of Media Selection and Implementation Steps in Learning," Journal of Islamic Thought, vol. 37, no. 1, pp. 27 - 33, Jun. 2012.

[9] N. Meilza dan A. Kurniawan, "The Influence of I-CHAT Learning Media on the Speaking Ability of Deaf Children," P3LB Journal, vol. 3, no. 1, Jul. 2016.

[10] I. Perdana, Introduction to Quantitative and Qualitative Research Methodology for English Language Learning. Banjarmasin: PT. Wangi Kalimantan, 2013

[11] D. P. Hallahan and J. M. Kauffman, Exceptional learner. Allyn and Bacon, 2006.

[12] A. Arda, S. Saehana, and D. Darsikin, "Development of ApplicationBased Interactive Learning Media," Science Partner Journal, vol. 3, no. 1, pp. $69-77$, Jan. 2015.

[13] I. Inung D. Kurniawati and S. Nita, "Learning Media Based on Interactive Multimedia to Improve Understanding of Concepts in Students", DoubleClick: Journal of Computer and Information Technology, vol. 1, no. 2, Feb. 2016.

[14] S. Supardi, L. Leonard, H. Suhendri, and R. Rismurdiyati, "The Influence of Learning Media and Interest in Learning Against Learning Outcomes," Formative Journal, vol. 2, no. 1, pp. 71 - 81, 2015.

[15] I. Falahudin, "Utilization of Media in Learning," Lingkar Widyaiswara Journal, vo. 1, no. 4, Dec. 2014

[16] T. Hernawati, "Development of Language and Speaking Ability of Deaf Children," Jassi Anakku, vol. 7, no. 1, pp. 101-110, Jun. 2007. 